\title{
Transcultural translation and adaptation of the Assessment Battery for Communication (ABaCo) for the Portuguese population
}

\author{
Nicole Agrela ${ }^{1}$ \\ https://orcid.org/0000-0002-9514-9689 \\ Maria Emília Santos ${ }^{2}$ \\ https://orcid.org/0000-0002-7575-4435 \\ Sandra Guerreiro ${ }^{3}$ \\ https://orcid.org/0000-0002-1367-5803
}

Universidade Católica Portuguesa, Instituto de Ciências da Saúde, Lisboa, Portugal

Universidade Católica Portuguesa, Instituto de Ciências da Saúde, Center for Interdisciplinary Research in Health (CIIS), Lisboa, Portugal

${ }^{3}$ Centro de Reabilitação Profissional de Gaia (CRPG), Vila Nova de Gaia, Portugal

Conflict of interests: Nonexistent

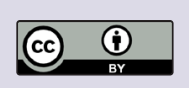

Received on: October 21, 2019

Accepted on: April 27, 2020

Corresponding address:

Nicole Agrela

Rua de São Bento, apartamentos

Coobrava, $n^{0} 14$, bloco $B, 5^{\circ} \mathrm{B}$

CEP: 9350-223 - Ribeira Brava - Portugal

E-mail: nicole_agrela@hotmail.com

\section{ABSTRACT}

Purpose: to perform the transcultural adaptation and translation of the $\mathrm{ABaCo}$ battery for the Portuguese population and check its psychometric properties.

Methods: initially, the translation and retroversion of $\mathrm{ABaCo}$ was done. A total of 40 participants without pathology were recruited. Two equivalent Forms (Form $A$ and Form B) were used, consisting of linguistic, extralinguistic, paralinguistic and context scales. The instrument was also applied to 12 people who were in the chronic phase after severe or moderate traumatic brain injury (TBI). For statistical analysis the following tests were used: Mann-Whitney $U$ test, Student $t$ test for independent samples, Pearson's correlation (the value is considered significant when $p \leq 0.05$ ) and Cronbach's alpha (the value is considered minimally acceptable when superior to 0.65).

Results: TBls' participants showed lower results as compared to those without neurological pathology. The evidence was discriminatory for the population with $\mathrm{TBI}$, although, on some scales, it was not, due to the ceiling effect. Differences were not found between the two Forms. The results also showed the existence of correlation of schooling and age with some of the components of $\mathrm{ABaC} 0$, as verified in the original version. No differences in gender-conditioned responses were found. The battery showed good metrical qualities with a Cronbach's alpha of 0.90 (Form A) and 0.71 (Form B), for the total sample.

Conclusion: $\mathrm{ABaCo}$ has proved to be an appropriate instrument for assessing communication in the Portuguese adult population. Despite the limitations, this instrument is expected to be useful in the evaluation of the communication, following TBI.

Keywords: Communication; Assessment; Traumatic Brain Injury 


\section{INTRODUCTION}

The ability to communicate effectively is essential in our daily lives. This ability is often impaired due to brain injuries, such as traumatic brain injury (TBI), becoming an obstacle to the social reintegration of these subjects ${ }^{1-6}$.

In terms of communication, pragmatic competence results from the interaction of several communicative skills activated in everyday contexts to convey a specific meaning ${ }^{7,8}$. This competence is generally impaired in subjects who have suffered TBI, i.e., they frequently present changes in the use of language in different contexts of everyday life, even in the long term $^{9}$. These changes cover several aspects, namely: euphoric, tangential and redundant speech; difficulties in organising the speech in a logical and sequential way and in adjusting the vocabulary to different contexts of daily life; decreased initiative and communicative inhibition/disinhibition; difficulties in meeting/ understanding the needs of the interlocutor, dispersing into irrelevant comments and details; difficulties in providing information in order to maintain and develop the conversation, in maintaining or changing appropriately the topic, and in respecting conversational turntaking; difficulties in making inferences from extensive and complex content; inappropriate use of gestures and facial expression, and changes in the recognition of prosodic features of discourse ${ }^{10-15}$.

Assessing communication after brain injury is essential for the rehabilitation process ${ }^{1,16-19}$ but this need is not always acknowledged ${ }^{20,21}$. This situation can be explained mainly by two reasons: difficulties in evaluating the different communicative abilities and the fact that TBI subjects speak better than communicate, without apparent linguistic impairment, which draw away the professionals' attention, even though their communication is often inappropriate and ineffective.

In recent years, more sophisticated assessment practices have been developed for TBI individuals regarding verbal communication (production, comprehension and metapragmatics ${ }^{15,22}$ ), and non-verbal communication, assessed in a natural context ${ }^{15}$ or in conversational situations between the TBI subject and an examiner ${ }^{23}$

Despite the relevance of these tests, a common limitation persists, which is the lack of equivalent Forms of the same test to avoid the possible learning effect, when the subjects are evaluated and re-evaluated before and after the rehabilitation programme.
The ABaCo battery (Assessment Battery for Communication $)^{10,24-26}$ does not present this limitation, as it presents two equivalent Forms (Form $A$ and Form B) that aim to assess and reassess the most relevant communicative components.

In Portugal, there aren't specific instruments to assess communication after brain injury. Therefore, experts considered important to adapt the $\mathrm{ABaCo}$, considering that, at an international level, this Italian version battery is the most complete evaluation instrument. This assessment is based on the visualisation of videos, without resorting to speech, and on short-answer questions, regarding everyday situations. Therefore, in addition to proper translation, it was only necessary to assure that the gestures portrayed in the videos and the test questions were appropriate for the Portuguese population.

The main objective of this study was to carry out the translation and cross-cultural adaptation of the $\mathrm{ABaCo}$ battery for the Portuguese population and to verify its psychometric properties.

\section{METHODS}

The methodology and research ethics were approved by the administration of the academic institution - Instituto de Ciências da Saúde (Institute of Health Sciences) of the Universidade Católica Portuguesa, in a document issued on February 12, 2018.

\section{Participants}

\section{Control group}

In order to test the suitability of the tests, a sample was recruited with identical characteristics to those from the original version ${ }^{24}$, i.e., individuals over 18 years of age and with different academic levels, since this variable could affect the results, as occurred in the Italian version. Forty volunteers from various origins were recruited, 16 male and 24 female, aged between 18 and 66 years old and with an academic level between the fourth grade and higher education (Table 1). Subjects who had a history of mental and/ or physical pathology that prevented or impaired the performance in the tests were excluded. 


\section{Clinical group}

Since the ABaCo is intended to assess the communicative ability in subjects who have suffered TBI, the adaptation of the battery also includes the evaluation of a clinical population in order to verify whether this test allows to discriminate the communication problems inherent in TBI. The participants were volunteers recruited from among the members of a non-profit association, named Novamente, designed to support and monitor people who have suffered brain injuries and their family members/caregivers. Most participants lived with their parents and/or caregivers, only one lived independently. Participation in the study implied the following inclusion criteria: (1) having suffered severe or moderate TBI; (2) being at least 18 years of age; (3) having more than a 12-month time period evolution; (4) being a native speaker of European Portuguese and (5) presenting a cognitive level and receptive/expressive communication ability that did not prevent or obstruct the test performance. Subjects with a history of mental and/or physical pathology that would prevent or hinder group participation were excluded. The 12 participants corresponded to the total number of people in the association who met the stated inclusion criteria (Table 1). These participants were part of a parallel study on the effectiveness of a communication rehabilitation programme, so they completed Form $\mathrm{A}$ before the programme started and Form $B$ at the end of the programme, 3 to 4 months later.

All participants, as well as family members/ caregivers of the clinical group, were informed about the objectives of the study and gave their informed consent and authorisation for audio-visual record (sound and image) for later analysis of the responses.

Table 1. Demographic characteristics of the sample in the control group $(n=40)$ and in the clinical group $(n=12)$

\begin{tabular}{|c|c|c|}
\hline Control Group & $\begin{array}{c}\text { Form A } \\
n=20\end{array}$ & $\begin{array}{c}\text { Form B } \\
n=20\end{array}$ \\
\hline \multicolumn{3}{|l|}{ Gender } \\
\hline Males & 8 & 8 \\
\hline \multirow[t]{2}{*}{ Females } & 12 & 12 \\
\hline & $M \pm S D$ & $\mathrm{M} \pm \mathrm{SD}$ \\
\hline Age & $43.90 \pm 14.73$ & $44.55 \pm 14.15$ \\
\hline Academic years & $10 \pm 4.4$ & $11.35 \pm 3.9$ \\
\hline Clinical Group & \multicolumn{2}{|r|}{$\begin{array}{c}\text { Form A e Form B } \\
n=12\end{array}$} \\
\hline \multicolumn{3}{|l|}{ Gender } \\
\hline Males & \multicolumn{2}{|r|}{9} \\
\hline \multirow{2}{*}{ Females } & \multicolumn{2}{|r|}{3} \\
\hline & \multicolumn{2}{|r|}{$\mathrm{M} \pm \mathrm{SD}$} \\
\hline Age & \multicolumn{2}{|r|}{$34.08 \pm 10.30$} \\
\hline Academic years & \multicolumn{2}{|r|}{$10.08 \pm 1.44$} \\
\hline
\end{tabular}

$\mathrm{n}$-sample number; $\mathrm{M}$ - average; SD -standard deviation

\section{Material}

The $\mathrm{ABaCo}$ consists of two equivalent Forms, as already mentioned, Form A and Form B, with many of the items based on videos (20-25 seconds each) whose main objective is to verify if the participant adequately comprehends or produces several communicative acts, according to what is requested. Although the performance in videos are made by Italian actors, the paralinguistic (facial expressions and prosody) and extralinguistic (gestures) aspects are culturally similar to those used in Portugal.
In the present study, four $\mathrm{ABaCo}$ scales were used: Linguistics, Extralinguistics, Paralinguistics and Context. These scales are divided into seven subscales: Linguistic comprehension; Linguistic production; Extralinguistic comprehension; Extralinguistic production; Paralinguistic comprehension; Paralinguistic production and Context subscale.

The Linguistic scale assesses the subject's ability to comprehend and produce questions, assertions, commands and requests [ex: Observer's Instruction: "Can I see your watch?"; "Your shirt is red."; "Show me 
where the window is."; "How old are you?". Instruction to be given by the Participant: "He wants to know where I live. What are you asking me? "; "Tell me what you think of my shirt."; "Tell me to speak lower."; "Ask me for a tissue."].

On the Extralinguistic scale, subjects are assessed on comprehension and production - questions, assertions, commands, requests and irony, by watching videos with actors who communicate by gestures [e.g.: Comprehension: The actor is hand holding a tray with chocolates. He tilts it towards the viewer, with a questioning expression, as if he is asking "Do you want it too?". After viewing the video, the participant must show that he/she has realized what the actor wanted to convey. Production: Observer's instruction: "Tell me the time through gestures."].

On the Paralinguistic scale, it is evaluated the subjects' ability to comprehend and produce relevant features that complement oral speech, such as facial expression and prosody [e.g.: Comprehension: "The actress is scared.", after viewing the video, the participant must indicate what emotion the girl is communicating. Production: instruction to be given to the participant: "Ask me where we can find a doctor. Ask me as if you are sad."].

The Context scale evaluates the subjects' ability to adjust their vocabulary to different contexts of everyday life [e.g. observer's instruction: "Imagine you are going to ask your husband/wife/mother if dinner is ready. How can you ask it?" "Imagine asking the waiter if the food is still taking a while to come. How can you ask him?"].

Regarding the quantitative analysis of each item, the various dimensions of each scale are presented on the score sheet, for example: form of expression (the subject comprehends or produces a certain communicative act according to the intonation and facial expression requested); conveyed content (the subject recognises or produces a communicative act adjusted to the question); disregard of the rules and its reason (the subject comprehends or produces a certain communicative act that involves deceit or irony); intended meaning (the subject comprehends or produces a specific gesture according to what is requested), and social appropriateness (the subject adjusts the communicative act to the context). Bearing in mind the subjectivity inherent in the evaluation of pragmatics, these dimensions help the examiners to guarantee the accuracy and objectivity of the attributed scores.
The ABaCo's scores range from 0 (incorrect response) to 1 (correct response), with a maximum total of 65 points in each Form. In the original version applied to a population of children with typical development, this battery showed good results in terms of internal consistency, validity and agreement between the examiners ${ }^{26}$. In the adult population, only the internal consistency of the test was evaluated based on the results of a group of TBI subjects ${ }^{25}$.

\section{Procedures}

In the $\mathrm{ABaCo}$ translation and adaptation process, the guidelines preconized by Beaton, Bombardier, Guillemin and Ferraz ${ }^{27}$ were followed:

- In the first stage, "translation", an authorisation request was made to the $\mathrm{ABaCo}$ authors to adapt the test to the Portuguese population. After the authors' approval, the original test was requested to be sent in Italian, since the published version was in English. A bilingual subject translated the test from Italian into European Portuguese (EP).

- In the second stage, "translation synthesis", special attention was paid to inaccuracies in inferences and in grammatical structures, at the syntactic, semantic, prosodic or cultural level. The final version was verified, concluding that there was no need to change it.

- In the third stage, "back translation", the Portuguese Italian test was back-translated by a bilingual subject.

- In the fourth stage, "expert committee review ", the translation and back translation were checked, with no need for changes.

- In the fifth stage, "pretesting", the test was administrated to three adult subjects without pathology. It was found that the protagonist performed a gesture that is not culturally used in Portugal in one of the videos, which led to interpretation problems. Thus, and with the authorisation of the authors of the original version, a new video was created with the appropriate gesture for the Portuguese population.

- In the sixth and final stage, "submission", the Portuguese version of the $\mathrm{ABaCo}$ was sent to the authors of the original test.

The various construction stages of the Portuguese version, according to the guidelines by Beaton et al. ${ }^{27}$, are summarized in Figure 1.

This test was administered to 40 participants from the control group, equally distributed between Form $A$ and Form B. The subjects were video recorded 


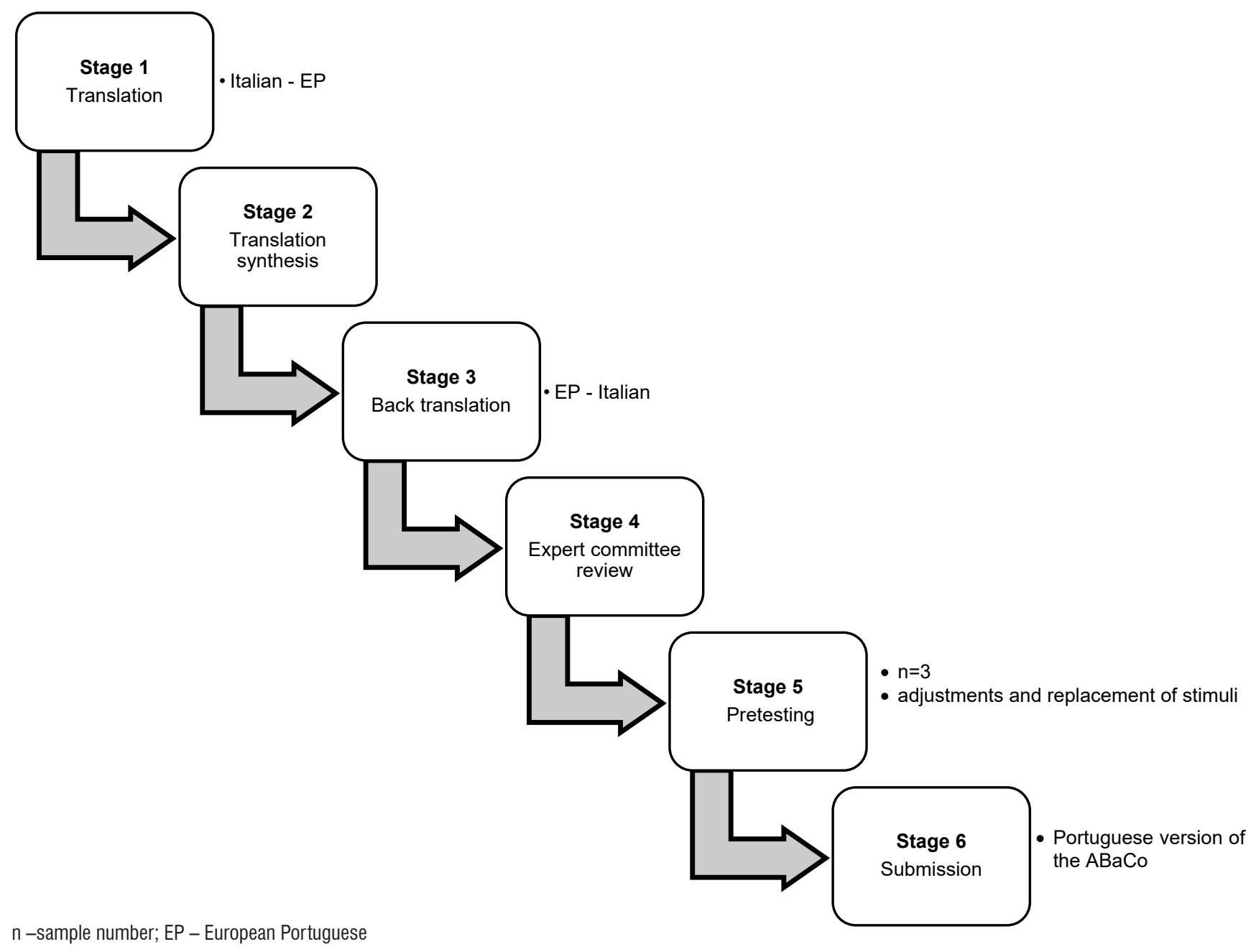

Figure 1. Stages in the $\mathrm{ABaCo}$ translation and adaptation process

during the application of the battery. Two independent examiners attributed the scores separately by viewing the videos and, subsequently, the scores were compared, with no discrepancies in the evaluation. Dispersion of responses was found for two of the four possible options regarding one of the videos in Form B, so all the correct responses were considered. The tests were applied individually in an average of 45 minutes.

After this process was completed, the 12 subjects in the clinical group were evaluated through the two Forms of the ABaCo: Form $A$, which was applied before the intervention programme, and Form $B$, after the programme (about 3 to 4 months later). The rehabilitation programme consisted of 24 sessions, aimed at improving communication skills in people who had suffered TBI.

For the statistical analysis, the following evaluation methods were used: the Mann-Whitney $U$ test, the
Student's T-test for independent samples, Pearson's correlation and Cronbach's alpha.

The Mann-Whitney $U$ test was used to compare the results obtained in the adaptation of the $\mathrm{ABaCo}$ in the control group and in the clinical group (the value is considered significant when $p \leq 0.05$ ).

Student's $t$ test for independent samples was used to check if there were significant differences between the results of Form A and Form B, for each of the different components and the effect of the variable gender on the test results (the value is considered significant when $p \leq 0.05$ ).

Pearson's correlation was used to correlate academic years and age with the ABaCo results (a correlation will be significant when $p \leq 0.05$ ).

Cronbach's alpha was used to check the internal consistency of the test (the value is considered minimally acceptable when superior to 0.65 ). 


\section{RESULTS}

The translation and adaptation process of the $\mathrm{ABaCo}$ for the Portuguese population consisted of six stages: translation, translation synthesis, back translation, expert committee review, pretesting and submission, according to the guidelines by Beaton et al. ${ }^{27}$.

\section{Results obtained in the adaptation of the $\mathrm{ABaCo}$ administered to the control group (40 subjects) and the clinical group (12 subjects)}

The average results obtained in the adaptation of the $\mathrm{ABaCo}$ are presented in Table 2 for participants in the control group and in the clinical group. The comparison between the results of the control population with those of the clinical group (Form A - before the intervention programme; Form B - after the programme) was performed using the Mann-Whitney $U$ test. It was found that, in Form A, there were significant differences in the two groups, with better results by the control group, regarding Paralinguistic production, Extralinguistic comprehension and production, and Context production. In the remaining subscales (Paralinguistic comprehension, Linguistic comprehension and production), no significant differences were found.

In Form B, it was verified that there are only significant differences between the two groups in the Paralinguistic production and in the Context scale, with better results shown by the control group, once more.

Table 2. Results obtained in the adaptation of the ABaCo in the control group (40 subjects) and in the clinical group (12 subjects)

\begin{tabular}{|c|c|c|c|c|c|c|c|c|c|}
\hline & \multirow[b]{2}{*}{$\begin{array}{l}\text { Maximum } \\
\text { score on } \\
\text { each scale }\end{array}$} & \multicolumn{4}{|c|}{ Form A } & \multicolumn{4}{|c|}{ Form B } \\
\hline & & 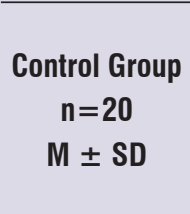 & $\begin{array}{c}\text { Clinical group } \\
\mathrm{n}=12 \\
\text { (before the } \\
\text { training) } \\
\mathrm{M} \pm \mathrm{SD}\end{array}$ & $\mathbf{U}^{*}$ & $p$ & $\begin{array}{l}\text { Control Group } \\
\begin{array}{c}n=20 \\
M \pm S D\end{array}\end{array}$ & $\begin{array}{c}\text { Clinical group } \\
\mathrm{n}=12 \\
\text { (after the } \\
\text { training) } \\
\mathrm{M} \pm \mathrm{SD}\end{array}$ & $U^{*}$ & $p$ \\
\hline $\begin{array}{l}\text { C. Paralinguistics } \\
\text { (facial expressions and } \\
\text { prosody) }\end{array}$ & 4 & $2.80 \pm 0.95$ & $2.67 \pm 1.30$ & 117.50 & .92 & $3.25 \pm .85$ & $2.83 \pm .83$ & 84.00 & .14 \\
\hline P. Paralinguistics & 6 & $6.00 \pm .00$ & $3.83 \pm 1.19$ & .00 & .00 & $6.00 \pm .00$ & $5.00 \pm 1.28$ & 60.00 & .001 \\
\hline C. Extralinguistics & 16 & $12.80 \pm 2.46$ & $9.33 \pm 2.81$ & 44.50 & .003 & $13.60 \pm 1.60$ & $13.42 \pm 1.31$ & 105.00 & .55 \\
\hline $\begin{array}{l}\text { P. Extralinguistics } \\
\text { C. Linguistics }\end{array}$ & 21 & $18.05 \pm 3.95$ & $12.42 \pm 2.19$ & 33.50 & .001 & $18.45 \pm 2.50$ & $18.33 \pm 2.39$ & 111.00 & .72 \\
\hline $\begin{array}{l}\text { (questions, assertions, } \\
\text { commands, requests) }\end{array}$ & 8 & $8.00 \pm .00$ & $8.00 \pm .00$ & 120.00 & 1.00 & $8.00 \pm .00$ & $8.00 \pm 0.00$ & 120.00 & 1.00 \\
\hline $\begin{array}{l}\text { P. Linguistics } \\
\text { P. Context }\end{array}$ & 8 & $8.00 \pm .00$ & $8.00 \pm .00$ & 120.00 & 1.00 & $8.00 \pm .00$ & $8.00 \pm 0.00$ & 120.00 & 1.00 \\
\hline $\begin{array}{l}\text { (vocabulary adequacy to } \\
\text { everyday contexts) }\end{array}$ & 2 & $2.00 \pm .00$ & $1.42 \pm .52$ & 50.00 & .000 & $2.00 \pm .00$ & $1.67 \pm 0.49$ & 80.00 & .007 \\
\hline
\end{tabular}

$\mathrm{C}$ - comprehension; $\mathrm{P}$ - production; $\mathrm{M}$ - average; SD -standard deviation; $\mathrm{n}$-sample number; $\mathrm{U}$ - Mann-Whitney $\mathrm{U}$ Test; $\mathrm{p}$ - significance level (the value is considered significant if $p \leq 0.05)$.

\section{Correlation of age, academic level and gender with the results in the $\mathrm{ABaCo}$, in the control group}

In order to verify if there were significant differences between the results of Form A and Form B, Student's $t$ test was used for independent samples for each of the different components. No significant differences were found in: Paralinguistic comprehension [t $(38)=-1.58$; $\mathrm{p}>$.05], Extralinguistic comprehension [t (32.65) = -1.22; $p>.05$ ] and Extralinguistic production [t $(32.12)=$
-.38; $\mathrm{p}>.05]$; in Paralinguistic production, Linguistic comprehension and production and in the Context scale, the results were exactly the same in both Forms.

To verify whether academic years and age had any effect on performance, Pearson's correlations were performed considering the total sample of 40 participants (Form A and Form B). It was possible to verify that there is no significant correlation between Paralinguistic comprehension and academic years $(r=.010, p>.05)$, 
but there is a moderate, extremely significant positive correlation between academic level and Extralinguistic comprehension $(r=.584, \quad p<.001)$, and between academic level and Extralinguistic production $(r=.598$, $p<.001$ ). Thus, the higher the academic level, the better the results in these tests. Age was not a significant variable in the results of Paralinguistic comprehension $(r=-.200, p>.05)$, but there were significant negative correlations with Extralinguistic comprehension ( $r=$ $-.510, p \leq .001)$ and with Extralinguistic production $(r=-.366, p<.05)$. Thus, the older the subjects, the lower the results in Extralinguistic comprehension and production.

In order to verify the effect of the gender variable on the test results, Student's $t$ test was performed for independent samples. It was possible to verify that there are no significant differences between men and women - Paralinguistic comprehension [t $(38)=-.84$; $\mathrm{p}>$.05], Extralinguistic comprehension [t $(38)=-.34$; $p>.05]$ and Extralinguistic production [t $(38)=.99$; $p>.05]$.
It was not possible to establish the correlations regarding the scales of Paralinguistic production, Linguistic comprehension and production and Context, since all participants responded correctly to all items. These outcomes indicate that academic level, age and gender variables do not affect the results.

\section{Internal consistency of the $\mathrm{ABaC}$ o}

The internal consistency was assessed by Cronbach's alpha for the total sample (40 participants in the control group and 12 participants in the clinical group), in order to increase the heterogeneity of the group, since the two samples were limited. Very good results were found in the Cronbach's alpha for form $A$ $(a=.90)$ and considerable results for form $B(a=.71)$ (Table 3). The scores obtained for the Paralinguistic and Extralinguistic scales were acceptable. It was not possible to obtain Cronbach's alpha for the Linguistics and Context scales since the verified variance was zero.

Table 3. Comparison of the results obtained regarding the internal consistency of the $\mathrm{ABaCo}$, Form $\mathrm{A}$ and Form $\mathrm{B}$

\begin{tabular}{lcc}
\hline Scales & Form A & Form B \\
\hline Paralinguistics (facial expressions and prosody) & .63 & .58 \\
Extralinguistics (gestures) & .88 & .62 \\
Linguistics (questions, assertions, commands, requests) & --- & --- \\
Context (vocabulary adequacy to everyday contexts) & --- & --- \\
\hline Total & .90 & .71 \\
\hline
\end{tabular}

\section{DISCUSSION}

Evaluating communication in TBI individuals is essential to be able to design an effective therapeutic intervention, thus improving their quality of life $^{17,18}$. However, communication, and specifically pragmatics, has not received the necessary attention in the rehabilitation programmes, which can be explained by the lack of assessment instruments ${ }^{28}$.

In the present study, translation and cross-cultural adaptation of the $\mathrm{ABaCo}$ battery ${ }^{10,24-26}$ were carried out for the Portuguese population, through the guidelines provided by Beaton et al. ${ }^{27}$ (translation, translation synthesis, back translation, expert committee review, pretesting and submission), consisting of an instrument designed mainly to assess the pragmatic features of communication. This battery has some indicative values for the Italian population, which is an asset in clinical practice, as it allows determining more accurately the degree of communicative impairments, in order to compare it with the expected results ${ }^{24}$.

The average scores were obtained and a comparison was made between the two Forms of the $\mathrm{ABaCo}$ (Form A and Form B) in a control group. The statistical results showed that the two Forms are equivalent, and that the average results obtained by the clinical group were inferior to those of the control group in some subscales.

Regarding the comparison of the results of the control group with those of the clinical group, it was found that, in Forms $A$ and $B$, there were significant differences in the ability to produce facial expressions, in prosody and in the adequacy of communicative 
acts, according to the different contexts. In Form A, there were still significant differences in the two groups concerning the recognition and production of gestures.

In Form B, there were less significant differences between the two groups, as would be expected, since the application of Form B, in the clinical group, was carried out after a communication rehabilitation programme, which greatly improved the communicative ability of these subjects. In general, it was found that the control group presented better results than the clinical group in both forms.

In the control population, it was also found that academic years and age have a significant effect on Extralinguistic comprehension and production, that is, on the one hand, the academic level affects positively the comprehension of gestures in particular situations of daily life and, on the other hand, older participants present worse results. In the original study ${ }^{24}$, there was only a correlation between academic level and Extralinguistic comprehension (not production), but with regard to age the results were identical to those of the present study. In Paralinguistic comprehension, no significant correlation was found concerning academic level or age, i.e., regardless those factors, the subjects had the same level of success in comprehending facial expressions and/or prosodic cues during the conversation. However, in the Italian study ${ }^{24}$, this correlation was significant, i.e., there was a positive correlation with the academic level, and a negative correlation with age, with worse results presented by older subjects. Cultural effects and especially the small sample size of the present study may explain the lack of significant effect. The results were identical between men and women. Moreover, the authors of the original study ${ }^{24}$ did not find, in general, gender-based differences. It should also be noted that the sample size of the control participants in this study, designed to verify the suitability of the $\mathrm{ABaCo}$ to the Portuguese population, is considerably smaller than that used by Angeleri et al..$^{24}$. Thus, some of the aforementioned results may differ in the two studies, not only due to cultural aspects, but also because the sample of the present study is relatively small.

Regarding the internal consistency of the test, considering the total sample, it was possible to verify a good reliability in Form A and in Form B. Although the value of Form $B$ was lower, it is still acceptable. The total score of Cronbach's alpha in Form A is very similar to the original study ${ }^{25}$ (Form $A: a=.92$ ), however, in Form B, the score is lower (Form B: $a=$
.95), certainly due to the small sample size assessed in the present study and to its greater homogeneity, with little variability in responses. In the Linguistic scale and in the Context scale, it was not possible to calculate the internal consistency for any of the Forms, as the variance was zero, since the subjects had the same results in all questions. Thus, despite the interest of this test to assess the communicative ability in TBI subjects, it presents an important limitation, which is the ceiling effect, for some of the scales (Paralinguistic production, Linguistic comprehension and production and Context production). In a future research, it would be important to increase the number of participants, either from the group of people without pathology, or from the clinical group, in order to obtain more consistent evaluation data and, eventually, to identify more easily the limitations of this battery.

\section{CONCLUSION}

The $\mathrm{ABaCo}$ translation and cross-cultural adaptation process was carried out in order to comply with the six stages proposed by Beaton et al. ${ }^{27}$. The following main conclusions were reached: (1) this evaluation instrument proved to be suitable for the studied population, since, as expected, TBI individuals showed lower results compared to those without neurological pathology; (2) the two forms of the battery (Form A and Form B) proved to be equivalent; (3) academic years and age had a significant effect on some $\mathrm{ABaCo}$ scales in the controls and (4), despite the ceiling effect observed on some of the scales, a good internal consistency was verified. Thus, even with some limitations, the $\mathrm{ABaCo}$ can contribute to a better assessment and rehabilitation of disabilities in terms of communication, and consequently improve the quality of life of people presented with TBI sequelae.

\section{REFERENCES}

1. Bosco FM, Angeleri R, Sacco K, Bara BG. Explaining pragmatic performance in traumatic brain injury: a process perspective on communicative errors. Int. J. Lang. Commun. Disord. 2015;50(1):63-83. https://doi.org/10.1111/1460-6984.12114

2. Maas Al, Menon DK, Adelson PD, Andelic N, Bell MJ, Belli $A$ et al. Traumatic brain injury: integrated approaches to improve prevention, clinical care, and research. Lancet Neurol. 2017;16(12):987-1048. https://doi.org/10.1016/S1474-4422(17)30371-X 
3. McDonald S, Fisher A, Flanagan S, Honan CA. Impaired perception of sincerity after severe traumatic brain injury. J Neuropsychol. 2017;11(2):291-304. https://doi.org/10.1111/ jnp.12086

4. Parola A, Bosco FM, Gabbatore I, Galettod V, Zettind M. The impact of the Cognitive Pragmatic Treatment on the pragmatic and informative skills of individuals with traumatic brain injury (TBI). J. Neurolinguistics. 2019;51:53-62. https://doi. org/10.1016/j.jneuroling.2018.12.003

5. Sacco K, Gabbatore I, Geda E, Duca S, Cauda F, Bara $B G$ et al. Rehabilitation of communicative abilities in patients with a history of TBI: behavioral improvements and cerebral changes in resting-state activity. Front Behav Neurosci. 2016;10(48):1-10. https://doi.org/10.3389/fnbeh.2016.00048

6. Wauters L, Marquardt TP. Disorders of emotional communication in traumatic brain injury. Semin Speech Lang. 2019;40(1):13-26. https://doi. org/10.1055/s-0038-1676364

7. Prutting CA. Pragmatics as social competence. J Speech Hear Disord. 1982;47(2):123-34.

8. Honan CA, McDonald S, Gowland A, Fisher A, Randall RK. Deficits in comprehension of speech acts after TBI: the role of theory of mind and executive function. Brain Lang. 2015;150:69-79. https://doi.org/10.1016/j.bandl.2015.08.007

9. Galski T, Tompkins C, Johnston MV. Competence in discourse as a measure of social integration and quality of life in persons with traumatic brain injury. Brain Inj. 1998;12(9):769-82.

10. Angeleri R, Bosco FM, Zettin M, Sacco K, Colle L, Bara BG. Communicative impairment in traumatic brain injury: a complete pragmatic assessment. Brain Lang. 2008;107(3):229-45. https://doi. org/10.1016/j.bandl.2008.01.002

11. Coelho CA, Youse KM, Le KN. Conversational discourse in closed-head-injured and non-braininjured adults. Aphasiology. 2010;16(4-6):659-72.

12. Drummond SS, Boss MR. Functional communication screening in individuals with traumatic brain injury. Brain Inj. 2004;18(1):41-56.

13. Green RE, Turner GR, Thompson WF. Deficit in facial emotion perception in adults with recent traumatic brain injury. Neuropsychologia. 2004;42(2):133-41.

14. McDonald S. Viewing the brain sideways? Right hemisphere versus anterior models of non-aphasic language disorders. Aphasiology. 1993;7(6):535-49.

15. Rousseaux M, Vérigneaux $C$, Kozlowski $O$. An analysis of communication in conversation after severe traumatic brain injury. Eur $\mathrm{J}$ Neurol. 2010;17(7):922-9.

16. Parola A, Gabbatore I, Bosco FM, Bara BG, Cossa FM, Gindri $P$ et al. Assessment of pragmatic impairment in right hemisphere damage. $J$ Neuropsychol. 2016;39:10-25. https://doi. org/10.1016/j.jneuroling.2015.12.003

17. Barman A, Chatterjee A, Bhide R. Cognitive impairment and rehabilitation strategies after traumatic brain injury. Indian $\mathrm{J}$ Psychol Med. 2016;38(3):172-81. https://doi. org/10.4103/0253-7176.183086

18. Gauthier S, LeBlanc J, Seresova A, Laberge-Poirier A, Correa J, Alturki AY et al. Acute prediction of outcome and cognitive-communication impairments following traumatic brain injury: the influence of age, education and site of lesion. $\mathrm{J}$ Head Trauma Rehabil. 2018;73(5):77-90. https:// doi.org/10.1016/j.jcomdis.2018.04.003

19. Kintz S, Hibbs V, Henderson A, Andrews M, Wright $\mathrm{HH}$. Discourse-based treatment in mild traumatic brain injury. J Commun Disord. 2018;76:47-59. https://doi.org/10.1016/j.jcomdis.2018.08.001

20. Bosco FM, Parola A, Angeleri R, Galetto V, Zettin M, Gabbatore I. Improvement of communication skills after traumatic brain injury: the efficacy of the Cognitive Pragmatic Treatment Program using the communicative activities of daily living. Arch Clin Neuropsychol. 2018;33(7):875-88. https://doi. org/10.1093/arclin/acy041

21. Frith M, Togher L, Ferguson A, Levick W, Docking $\mathrm{K}$. Assessment practices of speech-language pathologists for cognitive communication disorders following traumatic brain injury in adults: an international survey. Brain Inj. 2014;28(1314):1657-66. https://doi.org/10.3109/02699052.201 4.947619

22. Dardier V, Bernicot J, Delanoe A, Vanberten M, Fayada $C$, Chevignard $M$ et al. Severe traumatic brain injury, frontal lesions, and social aspects of language use: a study of French-speaking adults. J Commun Disord. 2011;44(3):359-78. https://doi. org/10.1016/j.jcomdis.2011.02.001

23. Sainson C, Barat $M$, Aguert $M$. Communication disorders and executive function impairment after severe traumatic brain injury: an 
exploratory study using the GALI (a grid for linguistic analysis of free conversational interchange). Ann Phys Rehabil Med. 2014;57(9-10):664-83. https:// doi.org/10.1016/j.rehab.2014.08.011

24. Angeleri R, Bosco FM, Gabbatore I, Bara BG, Sacco K. Assessment battery for communication (ABaCO): normative data. Behav Res Methods. 2012;44(3):845-61. https://doi.org/10.3758/ s13428-011-0174-9

25. Bosco FM, Angeleri R, Zuffranieri M, Bara BG, Sacco K. Assessment Battery for Communication: development of two equivalent forms. J Commun Disord. 2012;45(4):290-303. https://doi. org/10.1016/j.jcomdis.2012.03.002.

26. Sacco K, Angeleri R, Bosco FM, Colle L, Mate D, Bara BG. Assessment Battery for Communication - ABaCo: a new instrument for the evaluation of pragmatic abilities. J Cogn Sci. 2008;9:111-57.

27. Beaton DE, Bombardier C, Guillemin F, Ferraz MB. Guidelines for the process of cross-cultural adaptation of self-report measures. SPINE. 2000;25(24):3186-91.

28. Steel J, Togher L. Social communication assessment after TBI: a narrative review of innovations in pragmatic and discourse assessment methods. Brain Inj. 2018;10(4):1-14. http://dx.doi: 10.1080/02699052.2018.1531304 